\title{
Abundant protein-containing particles in the sea
}

\author{
Richard A. Long*, Farooq Azam \\ Marine Biology Research Division, Scripps Institution of Oceanography, University of California San Diego, La Jolla, \\ California 92093-0202, USA
}

\begin{abstract}
The interaction of bacteria with particulate organic matter has implications for organic matter cycling and bacterial ecology in the ocean. Until recently, the focus has been on 'classical' particles visible by unaided eye (marine snow) or light microscopy. Recent discoveries of several new types of abundant particles, from sub-micrometer to sub-marine snow, are changing our ideas of the physical and chemical nature of the particle field with which pelagic bacteria interact. Previous workers have discovered polysaccharide-containing (Alcian Blue stainable) transparent exopolymer particles (TEP) ranging from 3 to 100 s of micrometers. Looking for additional components of the submarine snow particle field, we took into consideration that since protein is a major component of biogenic organic matter, proteinaceous particles might also be abundant and important in bacteriaparticle interactions. We stained seawater with Coomassie Brilliant Blue G-250 (CBB), a protein stain, to reveal light to dark blue stained particles similar in shapes and size range to TEP. In samples filtered on Nuclepore filters, Coomassie Stained Particles (CSP) appeared globular, sheet- or string-like, while staining unfiltered water revealed 3-dimensional cloud-like shapes as well. Whether CSP are in fact TEP which also contain protein was tested by staining parallel samples with Alcian Blue and CBB (double staining a single sample was not possible since both dyes stain blue). CSP were 3 to 13 times more numerous and had up to 2 orders of magnitude greater area than TEP. Thus, while TEP and CSP may overlap, most CSP were distinct from TEP. Treatment of samples with Pronase E decreased CSP abundance and area by $78 \%$ and $96 \%$, respectively, confirming the proteinaceous nature of CSPs. The CSP abundance in coastal waters was $10^{6}$ to $10^{8} \mathrm{l}^{-1}$, and their area was $10^{2}$ to $10^{4} \mathrm{~mm}^{2} \mathrm{l}^{-1}$; both generally decreased with depth. Small particles were 2 to 3 orders of magnitude more abundant than large particles. Double staining with CBB and a fluorescent nucleic acid stain, DAPI, revealed that 20 to $40 \%$ of CSP were colonized by bacteria. Since they contain protein, CSP may serve as a $N$ source for bacteria and other organisms, and their production and utilization, which we did not study, may influence the flux and cycling of nitrogen in pelagic ecosystems.
\end{abstract}

KEY WORDS: Proteinaceous particles · Bacteria-particle interaction · Protein

\section{INTRODUCTION}

Organic matter in the ocean occurs as a size continuum of truly dissolved, colloidal and particulate phases including particles visible to the naked eye. In addition to the living organisms the particulate phase includes detrital particles of varied chemical compositions and sizes. These particles play major roles in the ocean's ecology and chemistry. They serve as food for animals and, after hydrolysis to the dissolved phase, as food for bacteria as well. They are a vehicle for the downward transport of organic matter in the water column.

•E-mail: ralong@ucsd.edu
Further, the dissolution and remineralization of the particulate phase are important processes for oceanic productivity and carbon cycling. It is therefore of interest to know the abundance, size-structure, composition and dynamics of the particle field in seawater.

In recent years, there has been a dramatic change in our knowledge of non-living particulate organic matter because of the discovery of new classes of highly abundant particles which had remained undetected by previous techniques. These range in size from sub-micrometer to hundreds of micrometers. Koike et al. (1990) using an electronic particle counter found $10^{10}$ particles $\mathrm{l}^{-1}$ from 0.38 to $1.0 \mu \mathrm{m}$ in size. They suggested that these particles are organic and have microbial sources and sinks. Wells \& Goldberg $(1992,1993)$ 
discovered $10^{11}$ to $10^{14}$ sub-micrometer particles $\mathrm{l}^{-1}$ by electron microscopy of samples sedimented by ultracentrifugation. Alldredge et al. (1993) discovered a class of transparent exopolymer particles (TEP) which could be visualized by staining with Alcian Blue (a dye that stains acidic mucopolysaccharides), apparently derived from phytoplankton (particularly diatoms) and bacteria. All TEP were colonized by bacteria (Passow \& Alldredge 1994) and in 2 studies $26-68 \%$ and $2-26 \%$ of the bacteria in surface water samples were attached to TEP (Alldredge et al. 1993, Passow \& Alldredge 1994). Very recently, Mostajir et al. (1995a, b) found a class of particles, 0.2 to $20 \mu \mathrm{m}$ in size, which stain yellow with 4', 6-diamidino-2-phenylindole (DAPI) (DAPI Yellow Particles or DYP) and occur at abundances of $10^{6} \mathrm{l}^{-1}$.

We are interested in the significance of organic particles in the ecology of pelagic bacteria and the biogeochemical conscquences of bacteria-particle interactions. Stimulated by the discoveries of 'new' particles, and considering that the macromolecular content of the biota is predominantly protein, we hypothesized that transparent proteinaceous particles should also be present and abundant in seawater. Since protein is a major source of nitrogen for pelagic bacteria, it was also of interest whether bacteria associate themselves with proteinaceous particles.

To test for the existence of transparent proteinaceous particles in seawater, we used Coomassie Brilliant Blue (CBB) G-250, a protein stain. CBB is commonly used in molecular biology to stain proteins in polyacrylamide gels and in biochemistry to quantify protein concentration in solution. These methods use low $\mathrm{pH}$ to increase color intensity and to linearize color yield as a function of protein concentration. A low pH staining protocol was undesirable for our purpose because it might lyse organisms and thereby increase the concentration of proteinaceous particles. The effect of $\mathrm{pH}$ on protonation of $\mathrm{CBB}$ and the formation of dye-protein complex has recently been studied. This study shows that CBB binds to proteins at neutral $\mathrm{pH}$ as well, and that the dye-protein complex formed at neutral $\mathrm{pH}$ is similar to that at low pH (Chial \& Splittgerber 1993), although the color yield is lower at neutral $\mathrm{pH}$. We developed a protocol based on staining at $\mathrm{pH} 7.4$ which we then used for the detection of proteinaceous particles in seawater.

\section{MATERIALS AND METHODS}

Sampling. Sampling was conducted off the Scripps Pier $\left(32^{\circ} 53^{\prime} \mathrm{N}, 117^{\circ} 15^{\prime} \mathrm{W}\right)$ by lowering a $1 \mathrm{l}$ polycarbonate flask into the upper $0.5 \mathrm{~m}$ of the sea surface on 7 December 1994, 27 March 1995, 12 and 14 May 1995, and 18 and 19 September 1995. The sample from 27 March 1995 was taken during a bloom dominated by the dinoflagellate Gonyaulax polyedra. Water samples were processed within $2 \mathrm{~h}$ of sampling. In addition, samples were obtained during the Arabian Sea U.S.-JGOFS (Joint Global Ocean Flux Study) process cruise \#1 at a coastal station (Stn $29,18^{\circ} 27^{\prime} \mathrm{N}, 57^{\circ} 18^{\prime} \mathrm{E}_{i} 31$ January 1995) and an open ocean station ( $\operatorname{Stn} 28,18^{\circ} 05^{\prime} \mathrm{N}$. $58^{\circ} 00^{\prime} E_{;} 29$ and 30 January 1995, Stn 28a and Stn 28b respectively). Water samples were collected in $10 \mathrm{l}$ Niskin bottles and processed within $2 \mathrm{~h}$. All samples were gently handled to minimize the possibility of disrupting fragile organisms and particles or creating particles by agitating dissolved organic matter (DOM).

Staining protocol. Coomassie Brilliant Blue G-250 ('Serva Blue G') was purchased from Serva (New York, NY, USA). A $1 \%(\mathrm{w} / \mathrm{v})$ stock solution in sterile Milli-Q water was prepared. Working solution was made daily by diluting the stock solution 25 -fold in $0.2 \mu \mathrm{m}$ filtered seawater to $0.04 \%$ (final) and $\mathrm{pH} 7.4$. The working solution was $0.2 \mu \mathrm{m}$ filtered for daily use. Samples of 1 to $25 \mathrm{ml}$ were filtered under low vacuum $(<200 \mathrm{~mm}$ $\mathrm{Hg})$ onto $0.2,0.8$ or $5.0 \mu \mathrm{m}$ polycarbonate filters (Nuclepore) backed by two $0.45 \mu \mathrm{m}$ HA filters (Millipore) placed on a fritted glass base. A glass or acrylic filtration tower was used. The backing filters, base, and tower were rinsed with Milli-Q water between samples. Immediately after filtration, with the filters still in the filtering unit, samples were stained by adding enough $\mathrm{CBB}$ working solution to cover the filter ( $350 \mu \mathrm{l}$ when using a glass tower and $30 \mu \mathrm{l}$ when using an acrylic tower). After staining for $30 \mathrm{~s}$ the stain was removed by vacuum filtration $(<200 \mathrm{~mm} \mathrm{Hg})$. Filters were transferred to frosted microscope slides (Cytoclear $^{\mathrm{TM}}$; Poretics Corp., Livermore, CA, USA) onto a drop of paraffin oil. These frosted slides permit transmitted light microscopy without the need to clear or dissolve the filter (Logan et al. 1994). A coverslip with a drop of paraffin oil on the downward side was placed on the filter. Slides were examined immediately or after storage at $4^{\circ} \mathrm{C}$ for up to 3 wk (Arabian Sea samples). An earlier control experiment showed that storage for at least $2 \mathrm{wk}$ did not change the abundance of the stained particles (data not shown).

Double staining with CBB and DAPI. Samples were processed as for CBB staining, except that DAPI ( $1 \mu \mathrm{g}$ $\mathrm{ml}^{-1}$ final concentration) was added to the samples 10 min prior to filtering onto black polycarbonate filters (Porter \& Feig 1980).

Alcian Blue staining. In order to compare the abundance of CBB-stained particles and TEP we stained selected samples in parallel. The method of Alldredge et al. (1993) as modified by Logan et al. (1994) was used. After filtration, with the filters still in the tower, the samples were stained with a $0.2 \mu \mathrm{m}$ prefiltered 


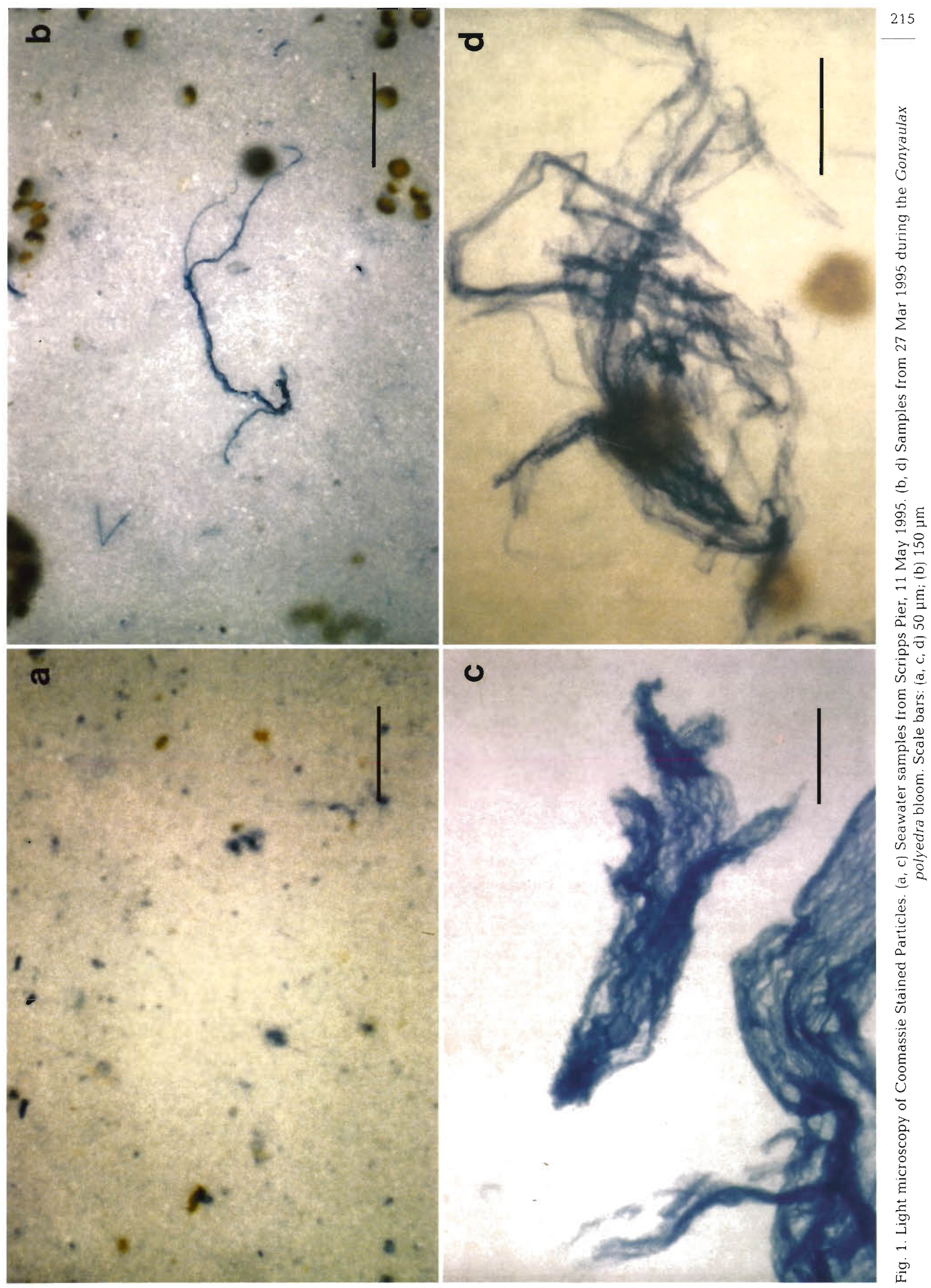


solution of $0.02 \%$ Alcian Blue $8 \mathrm{GX}$ (Sigma, A-9186) in $0.06 \%$ acetic acid ( $p H 3.3$ ) for $2 \mathrm{~s}$ and vacuum-filtered (150 to $200 \mathrm{~mm} \mathrm{Hg}$ ) to dryness. The filters were mounted as described above for CBB staining.

Blanks. Blanks for $\mathrm{CBB}$ and Alcian Blue staining were prepared to account for the background of stained particles derived from the reagents and other sources. Nuclepore filters were wetted with $0.2 \mu \mathrm{m}$ filtered seawater and then stained by the procedure used for the samples. Blanks were also prepared to test for the presence, albeit improbable, of naturally occurring blue particles in seawater. These blanks were prepared by filtering seawater onto Nuclepore filters and mounting the unstained samples.

Microscopy. Slides were examined by light microscopy at $312.5 \times$ magnification. Particles were sized and enumerated with a $10 \times 10$ ocular grid in which each grid opening had a projected dimension of $18 \times$ $18 \mathrm{\mu m}$. Particles from 20 to 40 random grids per filter were enumerated and sized. For sheet-like particles (see Fig. 1c, d) the particle size was measured along the longest dimension and the widest dimension perpendicular to it. Surface area was calculated assuming the particle to be a rectangle. For globular particles (see Fig. 1a) the longest diameter was measured and surface area was calculated by assuming the particle to be a circle. The calculated area was multiplied by 2 to account for the area of both sides of the particle. Colonization of particles with bacteria was examined in samples stained both with DAPI and CBB and viewed at $1000 \times$ and $1600 \times$.

Pronase E treatment. The purpose of this experiment was to determine the protease-lability of the Coomassie Staining Particles (CSP). In triplicate, $2 \mathrm{ml}$ seawater samples from 7 December 1994 were incubated with 1 unit $\mathrm{ml}^{-1}$ of bacterial Pronase E (type XIV, Sigma) at $20^{\circ} \mathrm{C}$ for $2 \mathrm{~h}$. Controls consisted of seawater without Pronase $\mathrm{E}$ addition. A blank was prepared to account for the presence of CBB-staining particles in the enzyme solution, by adding Pronase E to $0.2 \mu \mathrm{m}$ filtered seawater. The controls and the blank were incubated under the same conditions as the samples. All samples were filtered onto $0.2 \mu \mathrm{m}$ filters, stained with $\mathrm{CBB}$ and processed as above.

\section{RESULTS AND DISCUSSION}

\section{Particle characterization}

Staining seawater with CBB revealed abundant particles of varied sizes, shapes and 'textures' which stained bright to deep blue (Fig. 1). These included small (few $\mu \mathrm{m}$ ) globular particles (Fig. 1a), long strands, tens to hundreds of $\mu \mathrm{m}$ in length (Fig. 1b) and sheet-like particles of varied sizes from a few $\mu \mathrm{m}$ up to several hundred $\mu \mathrm{m}$ (Fig. 1c, d). Their thickness appeared to be highly variable between particles as well as in different parts of the same particle. We could not quantify particle thicknesses, and further, the particle dimensions were most probably significantly changed by filtration. This is suggested by our observation of unfiltered CSP, using a dissecting microscope. The larger particles $(>100 \mu \mathrm{m})$ which we observed in this manner had distinct and substantial third dimensions not discerned in the filtered samples. Some particles appeared gelatinous or had parts which appeared to be gelatinous. Manipulation of stained particles while viewing with the dissecting microscope gave the qualitative impression that the particles were sturdy, e.g. relative to most marine snow particles. Indeed, one might speculate that these sturdy subunits aggregate into marine snow and that marine snow might disintegrate into such sub-units. While we did not quantify their abundance, we observed some larger particles which had algal cells embedded in them.

Since $C B B$ stains protein, it could be concluded that the particles we observed contained protein, although we can not say what fraction of the particle's mass consisted of protein. In order to further confirm the proteinaceous nature of the particles we treated the samples with Pronase E, which is a highly non-specific protease, and predicted that this treatment would reduce or eliminate the CSP. Indeed, Pronase $E$ treatment caused a $78 \%$ reduction in CSP abundance and a $96 \%$ reduction in the particle area compared with a non-treated control (Fig. 2). The control itself decreased by $39 \%$ in particle abundance and increased by $70 \%$ in particle area during the $2 \mathrm{~h}$ incubation. We have not investigated the cause of changes in particle abundance and area in the control but they may indicate complex particle aggregation-disaggregation dynamics in seawater which may have been modified by the interactions of particle with the container walls. It is also relevant that Buroker-Kilgore \& Wang (1993) showed that CBB stains only larger peptides and proteins, and that it does not stain amino acids and smaller peptides. From this observation and the fact that the particles we observed are strongly stained we conclude that particulate and adsorbed protein is a substantial component of CSP.

\section{Particle abundance and area}

CSP abundance in surface water of Scripps Pier was on the order of $10^{7} \mathrm{I}^{-1}$ (Fig. 3). Cumulative area of CSP ranged from $10^{3}$ to $10^{4} \mathrm{~mm}^{2} \mathrm{l}^{-1}$. The largest values for both abundance and area were recorded during a 

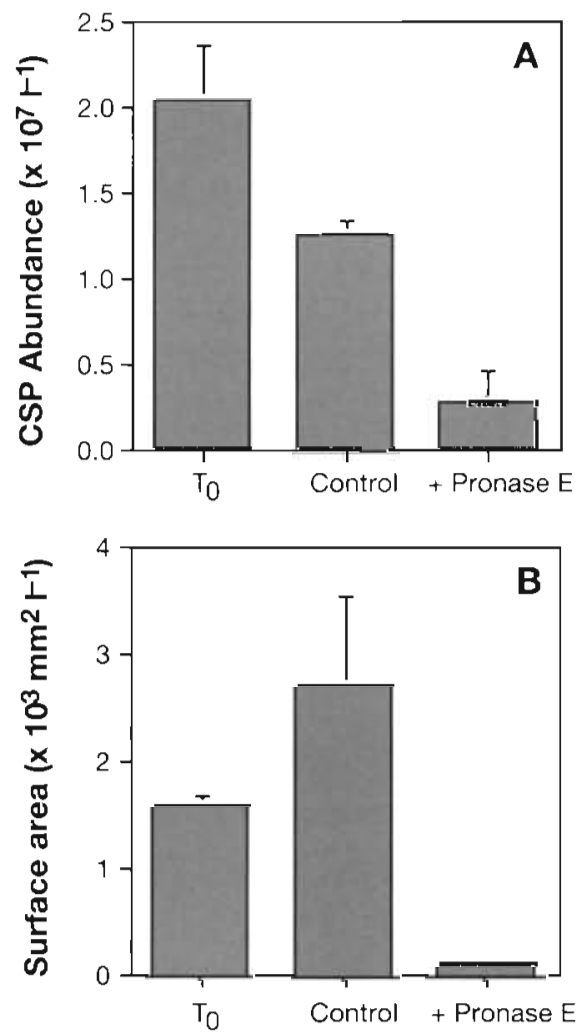

Fig. 2. Effect of $2 \mathrm{~h}$ Pronase E treatment of seawater samples from 7 Dec 1994. (A) CSP abundance, (B) surface area. $T_{0}$ : time zero. $\mathrm{N}=3$. Error bars $=\mathrm{SD}$

Gonyaulax polyedra bloom off Scripps Pier. CSP size distribution fitted a power curve such that the smaller $(<10 \mu \mathrm{m})$ fraction accounted for $>90 \%$ of CSP abundance and abundance decreased rapidly with increasing particle size (Fig. 4). The smaller fraction accounted for only a quarter of the area; hence, the larger but less abundant particles accounted for the majority of the surface area. It must be kept in mind that, due to the probable flattening of particles during filtration and because the calculation of area assumes a smooth particle surface, the actual surface area of the particles in all size classes is likely to be much larger.

The CBB working solution blanks accounted for $2.5 \%$ (abundance) and $2.6 \%$ (area) of the sample (7 December 1994 sample; Fig. 2). The absolute values of the blanks were fairly constant for the other samples which had higher areas and abundances; therefore, they had even lower \% blank values. Typically, then, the blank, and its variation, were not a significant factor in quantifying either CSP abundance or area.

The abundance of CSP in 3 depth profiles in the Arabian Sea ranged from $10^{6}$ to $10^{8} \mathrm{I}^{-1}$ throughout the water column (Fig. 5), with CSP abundance typically decreasing with depth. The size-frequency distribution
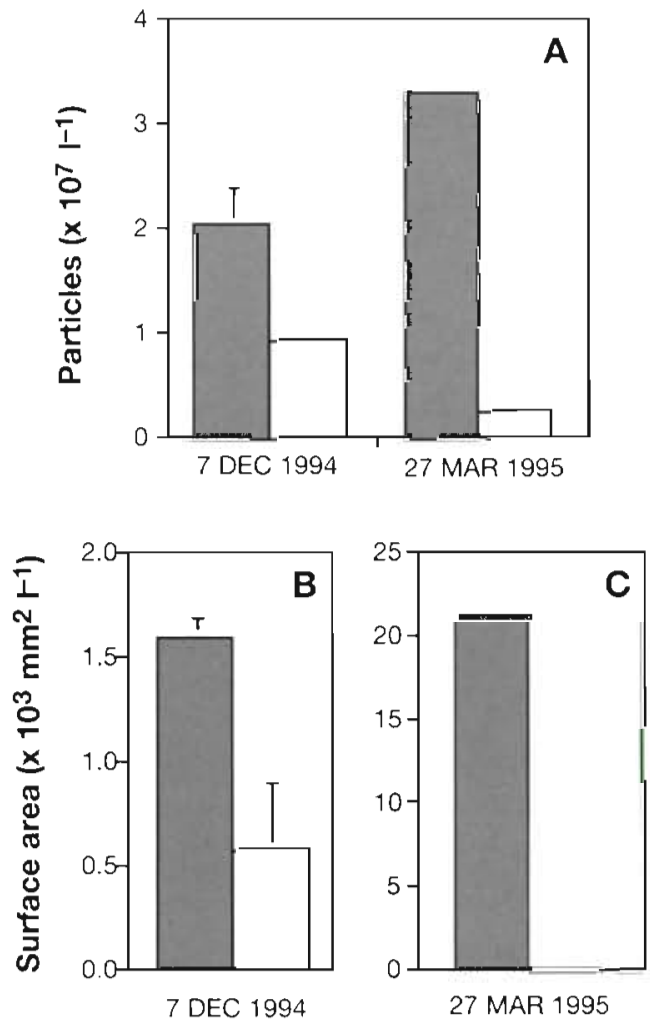

Fig. 3. (A) Abundance and (B, C) surface area of CSP ( $)$ and TEP ( $\square$ ) from surface seawater off Scripps Pier. The 27 Mar 1995 sample was taken during a Gonyaulax polyedra dominated bloom. $\mathrm{N}=3$. Error bar $=\mathrm{SD}$

fitted a power curve and was similar for all depths in the 3 profiles from the Arabian Sea, except for the $1500 \mathrm{~m}$ sample at Stn $28 \mathrm{~b}$. The cumulative area of the particles ranged from $10^{2}$ to $10^{4} \mathrm{~mm}^{2} \mathrm{l}^{-1}$. It decreased with depth (Fig. 5) except for the deepest sample at Stn 29 (the water depth at this station was $80 \mathrm{~m}$ and the

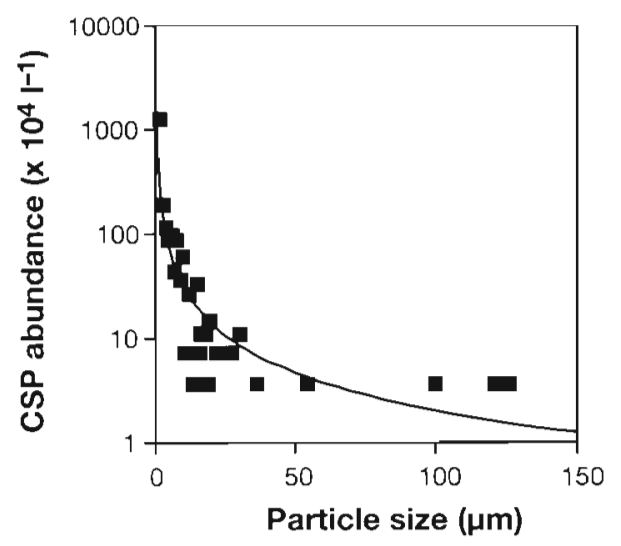

Fig. 4. Size distribution of CSP from 7 Dec 1994 off Scripps Pier We sized 569 particles $\geq 2 \mu \mathrm{m}$. The data best fitted to the power function $y=4974 x^{\cdot 1.202}$ with $r^{2}=0.750$ 
bottom water sample, having been taken only a few meters above the bottom, may have been influenced by sediment resuspension).

\section{Relationship to other particle classes}

Whether the CSP are in fact TEP which also contain protein was tested by staining parallel samples with Alcian Blue and CBB (double staining with these 2 protocols was not feasible since both dyes are blue). In the samples examined, the abundance and the surface area of CSP exceeded that of TEP. In samples from 7 December 1994, the abundance of TEP was $36 \%$ of that for CSP, while TEP surface area was $45 \%$ of CSP (Fig. 3). More striking was the contrast between CSP and TEP values in the samples from the Gonyaulax polyedra bloom. TEP abundance and surface area were $7.6 \%$ and $<1 \%$, respectively, of the values for CSP. Thus, while TEP and CSP may overlap, most CSP in these samples were distinct from TEP. It is possible, and likely, that some particles stain for both polysaccharide and protein

Proteinaceous as well as carbohydrate-containing particles have previously been reported (Gordon 1970). However, the reported abundances of the proteinaceous particles were 1 to 3 orders of magnitude lower than those reported here. Gordon (1970) used a Bromophenol Blue staining method (Mazia et al. 1953), so we do not know whether the higher abundances found by us are due to differences in methodology or due to real differences between their samples and ours. Direct comparisons were not performed since Gordon's method for staining proteinaceous particles
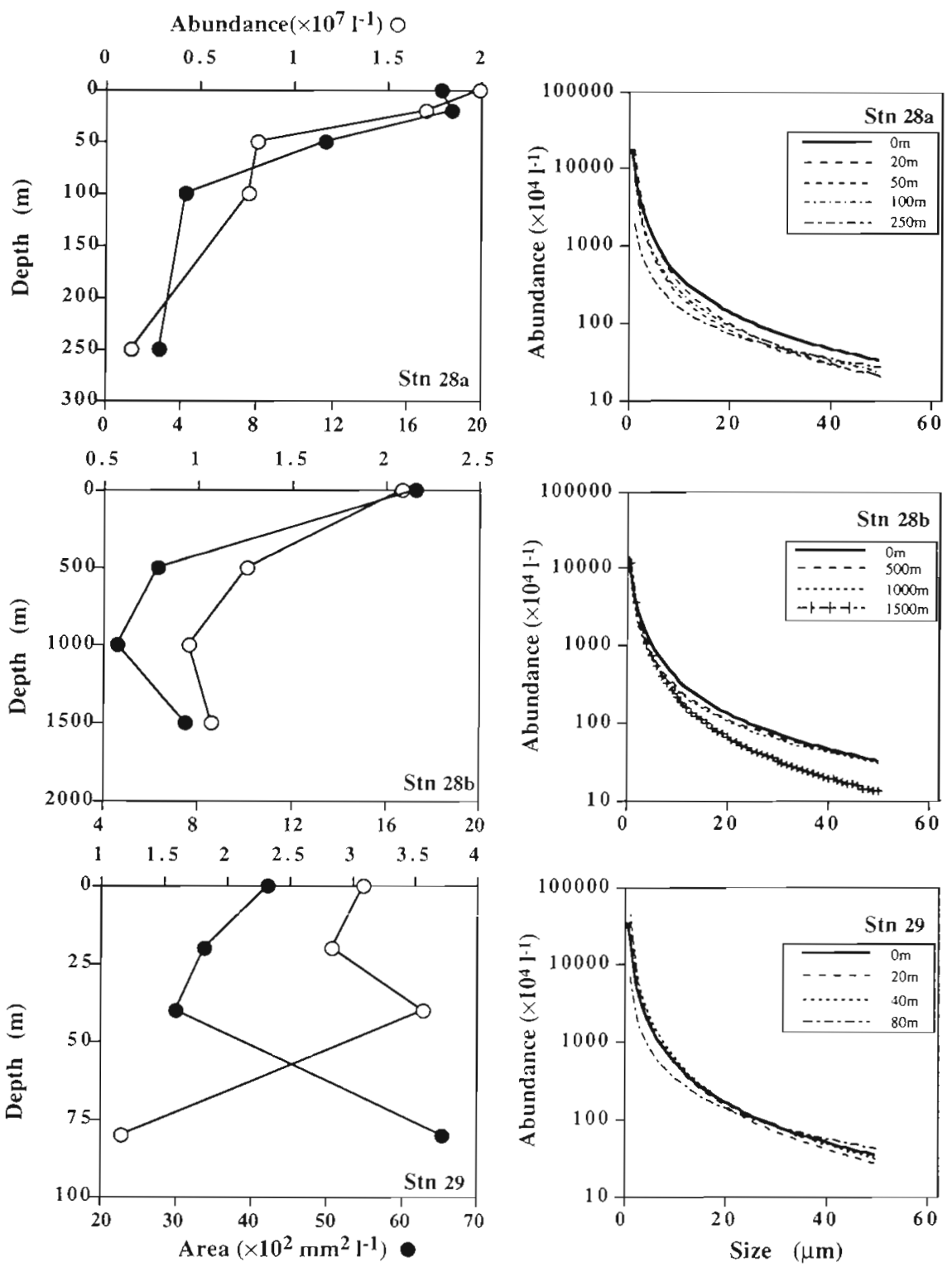

Fig. 5. Depth profiles of CSP abundance and area, and size distribution at Stns 28a, 28b and 29 from the Arabian Sea. To the right are corresponding plots of power functions of CSP size distribution. $\mathrm{r}^{2}$ ranged from 0.693 to 0.892 with a median of 0.830 


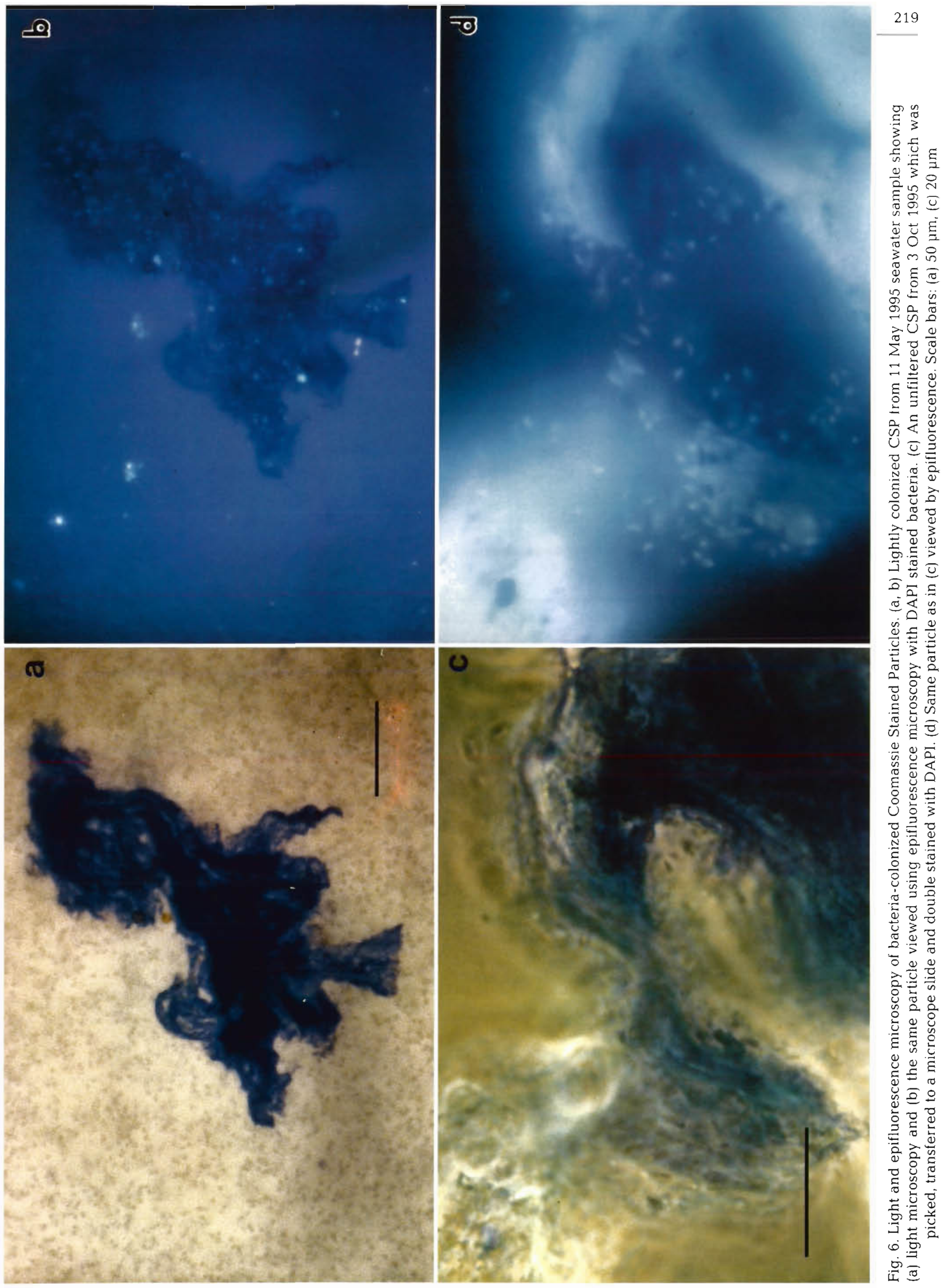


involved the addition of mercuric chloride and ethanol, which would permeabilize the algal and bacterial cells releasing internal proteinaceous material. We also note that the abundances of carbohydrate-containing particles in the surface waters found in the study of Gordon (1970) were also lower than those reported by Passow \& Alldredge (1994). The DYPs found by Mostajir et al. (1995b) are in the size range of 0.2 to $20 \mu \mathrm{m}$ and their DAPI staining components are organic; $\sim 90 \%$ are degraded by an enzyme cocktail which includes Proteinase $\mathrm{K}$ and lysozyme. Their abundance $\left(10^{6}\right.$ to $\left.10^{8} \mathrm{l}^{-1}\right)$ is comparable to that of CSP. However, the area of DYPs (43 to $278 \mathrm{~mm}^{2} \mathrm{l}^{-1}$ ) was at the lower range of the area of CSP found by us (200 to $20000 \mathrm{~mm}^{2} \mathrm{l}^{-1}$ ). Some of these particle classes may overlap, but quantifying such overlap requires new protocols to simultaneously detect staining with several stains.

\section{Bacterial colonization}

Twenty to $40 \%$ of CSP off Scripps Pier contained attached bacteria. The bacterial abundance per particle on the colonized CSP ranged from 1 to 38 (means $=5-8$ ). This represents on the order of $10^{7}$ bacteria $\mathrm{I}^{-1}$ of seawater being associated with CSP. We think these are underestimates on 2 accounts. First, we could observe only 1 face of the filtered particles, and this may have caused underestimation of the abundance per CSP and possibly also the \% particles colonized. Second, the bright to deep blue CBB stain tended to mask or quench the DAPI fluorescence. This problem can be seen in the particle shown in Fig. 6a, b, which is also an example of a highly colonized CSP in unamended seawater. In our experience of comparing samples on several epifluorescence microscopes, visualization of DAPI-stained bacteria on CSP is difficult with microscopes that have weak or older light sources and delaminated DAPI filter sets. Double staining of samples with $\mathrm{CBB}$ and Acridine Orange was attempted; however the dyes were incompatible. A few unfiltered CSP were picked and transferred to a slide where they were DAPI stained (Fig. 6c, d). The bacteria on them could be seen associated with gelatinouslooking regions of the particles.

\section{Origin and fate of CSP}

Although our study did not address the origins of CSP, they are likely to be diverse. Considering the broad distribution of protein in cellular particulate components, various mechanisms of cell lysis or death could lead to the production of protein-containing par- ticles. Further, adsorption of protein onto nonproteinaceous particles could render them CSP positive. It is therefore unlikely that a single or few sources of CSP will be found. In view of this, we have decided to define these particles only operationally as Coomassiestained particles. Since CSP spans a broad size range, their protein may potentially be utilized by a variety of organisms. The finding of extensive attachment of bacteria with CSPs might indicate their significance in bacterial nutrition. Pronase E sensitivity also supports the possibility that protein in the particles would not resist bacterial proteases (e.g. by glycosylation; Keil \& Kirchman 1993). The small CSP are most abundant $\left(10^{7} \mathrm{I}^{-1}\right)$ and they are in the size range where they may be eaten by protozoa. Larger CSP might be eaten by metazoa. However, we have not examined these possibilities thus far. Future studies should also measure the protein content of CSP in order to help place CSP in the context of the overall POC and PON dynamics in seawater and to gauge their possible significance for bacterial protein demand.

Acknowledgements. We thank Drs 丸. Hagström, J. T Hollibaugh and I. Koike for their discussions and Dr D. C. Smith, G. F. Steward, J. Y. Chung and the anonymous reviewers for their constructive comments on the manuscript. This study was supported by NSF grants from Biological Oceanography and Chemical Oceanography (JGOFS) to F.A.

\section{LITERATURE CITED}

Alldredge AL, Passow U, Logan BE (1993) The abundance and significance of a class of large, transparent organic particles in the ocean. Deep Sea Res 40:1131-1140

Buroker-Kilgore M, Wang KKW (1993) A Coomassie brilliant blue-G-250-based colorimetric assay for measuring activity of calpain and other proteases. Analyt Biochem 208: $387-392$

Chial HJ, Splittgerber AG (1993) A comparison of the binding of Coomassie brilliant blue to proteins at low and neutral pH. Analyt Biochem 213:362-369

Gordon DC (1970) A microscopic study of organic particles in the North Atlantic Ocean. Deep Sea Res 17:175-185

Keil RG, Kirchman DL (1993) Dissolved combined amino acids: chemical form and utilization by marine bacteria. Limnol Oceanogr 38:1256-1270

Koike I, Shigemitsu H, Kazuki T, Kogure K (1990) Role of submicrometer particles in the ocean. Nature 345:242-244

Logan BE, Grossart HP, Simon M (1994) Direct observation of phytoplankton, TEP and aggregates on polycarbonate filters using brightfield microscopy. J Plankton Res 16: $1811-1815$

Mazia DP, Brewer PA, Alfert M (1953) The cytochemical staining and measurement of protein with mercuric bromophenol blue. Biol Bull Mar Biol Lab, Woods Hole 104:57-67

Mostajir B, Dolan JR, Rassoulzadegan F (1995a) A simple method for the quantification of a class of labile marine pico- and nano-sized detritus: DAPI Yellow Particles (DYP). Aquat Microb Ecol 9:259-266 
Mostajir B, Dolan JR, Rassoulzadegan F (1995b) Seasonal variations of pico- and nano-detrital particles (DAPI Yellow Particles, 'DYP') in the Ligurian Sea (NW Mediterranean). Aquat Microb Ecol. 9:267-277

Passow U, Alldredge AL (1994) Distribution, size and bacterial colonization of transparent exopolymer particles (TEP) in the ocean. Mar Ecol Prog Ser 113:185-198

Responsible Subject Editor: J. T. Hollibaugh, Tiburon, California, USA
Porter KG, Feig YS (1980) The use of DAPI for identifying and counting aquatic microflora. Limnol Oceanogr 25: 943-948

Wells ML, Goldberg ED (1992) Marine submicron particles. Mar Chem 40:5-18

Wells ML, Goldberg ED (1993) Colloid aggregation in seawater. Mar Chem 41:353-358

Manuscript first received: November 14, 1995

Revised version accepted: March 16, 1996 